Науковий вісник НлТУ України Scientific Bulletin of UNFU

https://nv.nltu.edu.ua

https://doi.org/10.36930/40310202

Article received 06.04.2021 p.

Article accepted 29.04.2021 p.

UDC 582.635.1:630.2(477.4)
ISSN 1994-7836 (print)

ISSN 2519-2477 (online)

$@$ Correspondence author

S. A. Maslovata

svetlanamaslovatay@gmail.com

С. А. Масловата, М. Ю. Осіпов, О. М. Баюра, І. Є. Іващенко

Уманський нацуінальний університет садівництвва, м. Умань, Україна

\title{
ВЕГЕТАТИВНЕ РОЗМНОЖЕННЯ ДЕКОРАТИВНИХ ФОРМ ВИДІВ РОДУ ULMUS L. МЕТОДОМ ЩЕПЛЕННЯ
}

\begin{abstract}
Важливим завданням, без виконання якого неможливе розширення асортименту деревних рослин, що сприятиме збереженню їхнього біорізноманіття та раціональному використанню рослинних ресурсів, є встановлення їх репродуктивної здатності та найоптимальніших методів розмноження. Наведено результати дослідження та узагальнення роботи щодо особливостей вегетативного розмноження і вирощування садивного матеріалу видів і форм роду Ulmus у Правобережному Лісостепу України. Досліджено вегетативне розмноження декоративних форм видів роду Ulmus L. використовуючи окулірування та способи копулювання: "вприклад", "поліпшений вприклад" і "модифікований В. Ф. Собченком поліпшений вприклад" у ранньовесняний період та літнє окулірування в першій декаді серпня на підщепах U. laevis та U. glabra. Під час окулірування в першій декаді серпня найвищою приживлюваністю вирізнялися $U$. g. 'Pendula'(80,5\%) та U. g. 'Rubra' (79,0\%) на підщепі U. glabra, водночас, істотної різниці між ними не виявлено. Найнижча приживлюваність (39,5 \%) характерна декоративній форма U.g. 'Crispa Pyramidalis'. Варто відзначити, що майже всі декоративні форми видів роду Ulmus, окрім U. g. 'Crispa Pyramidalis', за всіх способів щеплення мали доволі високу приживлюваність при щепленні трирічних сіянців $U$. glabra (63,0 -100\%). За результатами щеплення декоративних форм видів роду Ulmus на U. laevis найкращі результати отримано в декоративних форм - U. g. 'Pendula' та $U . g$. 'Rubra' (76,0-98,5 \%). Середні показники приживлюваності спостерігали в $U$. g. 'Albo-variegata' (60,0-79,0 \%). Треба зазначити, що $U . g$. 'Crispa Pyramidalis', оскільки і під час щеплення на $U$. glab$r a$, вирізнялась найнижчою приживлюваністю (38,5-66,0 \%). За розмноження декоративних форм $U . g$. 'Pendula', $U$. g. 'Albovariegata', U. g. 'Crispa Pyramidalis' та $U . g$. 'Rubra' щепленням найвищий вихід щеп виявлено на підщепі U. glabra - 63-100 \%, з використанням способу копулювання наприкінці лютого - на початку березня. Отже, для розмноження усіх досліджених декоративних форм видів роду Ulmus найкращими в ранньовесняний період вегетації виявилися окулірування і такі методи копулювання: "поліпшений вприклад", "модифікований (СВФ) поліпшений вприклад" і "вприклад", а в ролі підщепи доцільно використовувати U. glabra і U. laevis.
\end{abstract}

Ключові слова: розмноження; щеплення; копулювання; окулірування.

\section{Вступ}

Методи щеплення рослин використовують 3 давніх часів [2]. Історію щеплень описували Дюгамель та Моліш $[3,7]$. А найбільше наукових праць з вивчення методів щеплень припало на середину ХХ ст. [9]. Останнім часом трапляються публікації методик для використання уже відомих способів щеплень $[1,8,9]$. Проте всі вони розраховані на щеплення в період інтенсивного росту прищепи, що припадає на завантажений веснянопольовими роботами час: кінець березня, квітень і травень. Про щеплення в ранньовесняний період, як менш завантажений, звернуто увагу ще 1925 року [9]. У період спокою в рослин камбій не росте, й відділення кори не простежується, тому щеплення треба робити тільки методами вприклад, поліпшений вприклад, у розщіп та окуліруванням [4]. Щеплення ж у зимовий період проводять тільки в лабораторних чи тепличних або підвальних приміщеннях на підщепах, викопаних восени, та живцями, заготовленими 3 осені. Методика грунтується на виведенні підщепи зі стану спокою в тепличних умовах, на яку і прищеплюється живець, що перебуває ще в стані спокою [9]. Ми ж застосували щеплення та окулірування в ранньовесняний, а потім і в літній періоди, тому що це найменш завантажений садовопольовими роботами період. Також було завдання застосувати методику прямого щеплення з дерева на дерево: тобто на підщепу в польових умовах прищепити живець, зрізаний у цей же час чи за кілька годин або днів раніше.

Питанням вегетативного розмноження деревних рослин способами щеплення в літературі приділяють

Інформація про авторів:

Масловата Світлана Андріївна, канд. с.-г. наук, ст. викладач, кафедра лісового господарства. Email: svetlanamaslovatay@gmail.com; https://orcid.org/0000-0002-5725-0604

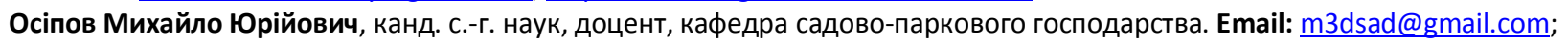
https://orcid.org/0000-0001-7004-1164

Баюра Олександр Михайлович, канд. с.-г. наук, доцент, кафедра лісового господарства. Email: sasha-uman@ukr.net; https://orcid.org/0000-0003-1679-5840

Іващенко Ірина Євгеніївна, канд. с.-г. наук, доцент, кафедра лісового господарства. Email: Ivashchenko_iy@ukr.net; https://orcid.org/0000-0001-5831-8490

Цитування за ДСтУ: Масловата С. А., Осіпов М. Ю., Баюра О. М., Іващенко І. Є. Вегетативне розмноження декоративних форм видів роду Ulmus L. методом щеплення. Науковий вісник НлтУ України. 2021, т. 31, № 2. C. 16-20.

Citation APA: Maslovata, S. A., Osipov, M. Yu., Bayura, O. M., \& Ivashchenko, I. Ye. (2021). Vegetative propagation of ornamental forms of species of the genus Ulmus L. Scientific Bulletin of UNFU, 31(2), 16-20. https://doi.org/10.36930/40310202 
значну увагу. Як зазначає В. Г. Козлов [4], завдяки щепленню можна раціонально розмножити навіть породи, які важко розмножуються іншими способами вегетативного розмноження. Особливо цінний цей спосіб розмноження для декоративних форм, які дають розщеплення під час посіву насіння. Також щепленню часто віддають перевагу перед іншими способами вегетативного розмноження, тому що сильний початковий ріст щеп швидше приводить до кінцевого результату - отримання високоякісних копій материнської рослини [1].

Об'єкт дослідження - декоративні форми видів роду Ulmus - U. g. 'Pendula', U. g. 'Albo-variegata', U. g. 'Rubra' та $U . g$. 'Crispa Pyramidalis'.

Предмет дослідження - розмноження декоративних форм окуліруванням та методами копулювання: "вприклад", "поліпшений вприклад" і "модифікований В. Ф. Собченком поліпшений вприклад".

Мета роботи - проаналізувати найоптимальніші методи вегетативного розмноження декоративних форм видів роду Ulmus на підщепах U. glabra та U. laevis в умовах Правобережного Лісостепу України.

Для досягнення зазначеної мети визначено такі основні завдання дослідження: визначити приживлюваність та ступінь зростання прищепи з підщепою методами копулювання: "вприклад", "поліпшений вприклад" "модифікований В. Ф. Собченком поліпшений вприклад" та окуліруванням.

Наукова новизна отриманих результатів дослідження - вперше для умов Правобережного Лісостепу України проаналізовано найоптимальніші методи вегетативного розмноження декоративних форм видів роду Ulmus: U. g. 'Pendula', U. g. 'Albo-variegata', U. g. 'Rubra' та $U . g$. 'Crispa Pyramidalis' на трирічних підщепах U. glabra та U. laevis у ранньовесняний період вегетації, а також влітку - повторне окулірування.

Практична значущість результатів дослідження обгрунтування оптимальних методів та термінів проведення вегетативного розмноження декоративних форм видів роду Ulmus в умовах Правобережного Лісостепу України.

Аналіз останніх досліджень та публікацій. У природних умовах види роду Ulmus вегетативно поновлюються відсадками, пневою і кореневою порослю. Останні два способи поновлення спостерігали у Національному дендропарку "Софіївка" НАН України після санітарних і ландшафтних рубок самосіву у паркових насадженнях. Вони виникали внаслідок партикуляції при відмиранні (механічному пошкодженні) ділянок кореневища або кореня, що з'єднують окремі парціальні утворення.

Оскільки представники роду Ulmus утворюють пневу поросль як природним, так і травматичним шляхом, то спостережувана у парку "Софіївка" поросль, яка з'являлася на пні, в перші роки свого життя відрізнялася дуже швидким зростанням порівняно 3 одновіковими рослинами насіннєвого походження, оскільки вона використовувала велику кількість запасних пластичних речовин, відкладених у материнському пні й корінні, адже нічого не витрачала на утворення нової кореневої системи

Також найбільш типовим способом вегетативного поновлення U. glabra та U. laevis є відновлення гіпо- та епігеогенними кореневищами (ксилоризомами) - зауважує А. А. Чистякова (1978), що ми також спостерігали у заповідних насадженнях парку "Софіївка". Формуван- ня кореневищ здійснювалось різними способами. Поперше, вони виникали 3 надземних бруньок в основі стовбура, утворюючи плагіотропні пагони; по-друге, при виляганні і подальшому укоріненні стовбурів у особин підросту, що складалися 3 гіпокотиля та пагонів першого порядку, i, по-трете, при виляганні та вкоріненні нижніх гілок унаслідок механічного притискування або природного низького розташування гілок. В останніх двох випадках виникали плагіотропні пагони, які ростуть спочатку надземно, але пізніше покривалися підстилкою і втягувалися в землю, утворюючи додаткові корені. Як наслідок - формувалася куртина - система ортотропних і плагіотропних пагонів, які не втрачали зв'язок один з одним і з материнським організмом. Вони були з'єднані багаторічними лігніфікованими епігеогенними кореневищами - ксилоризомами $[5,6]$.

Досліди 3 розмноження представників роду Ulmus кореневими живцями в культурі показують їх високу (95-100 \%) приживлюваність [7].

Декоративні форми й сорти рослин, які не утворюють насіння, а також гібридні рослини, які мають різні аномальності за формою листків, їх забарвленням, особливістю кори, махровістю квіток та іншими декоративними ознаками, що закріплені в цитоплазмі або в тканинах меристеми, розмножуються тільки вегетативно. Саме тому для розмноженні декоративних форм видів роду Ulmus ми використовували такий вегетативний спосіб розмноження, як щеплення.

У 1987-2004 pp. В. Ф. Собченко досліджував розмноження декоративних і плодових рослин методом щеплення свіжозрізаними живцями в період спокою, в тому числі й одного виду та чотирьох декоративних форм роду Ulmus: $U$. japonica, $U . \times$ hollandica 'Joculini Hillrevti', U. g. 'Pendula', U. g. 'Piramidale' та U. g. 'Rubra' [9].

матеріали та методи дослідження. Для розмноження декоративних форм видів роду Ulmus застосовано окулірування та методи копулювання: "вприклад", "поліпшений вприклад" i "модифікований В. Ф. Собченком поліпшений вприклад" у кінці лютого і на початку березня (ранньовесняний період). Влітку, в першій декаді серпня, використовували окулірування [9]. Прищепним матеріалом слугували свіжозрізані живці, а також живці, термін зберігання яких був мінімальним (до десяти діб) у холодильній камері за температури близько $0{ }^{\circ} \mathrm{C}$. У ролі підщепних штамбів використовували трирічні сіянці U. glabra та U. laevis.

Клімат району досліджень помірний, м'який, 3 порівняно теплою зимою і частими відлигами. Дослідження проводили у третій декаді лютого за хмарної погоди в світловий час доби, коли температура не опускалася за нуль. За даними Уманської гідрометеорологічної станції, яка розміщена на території Уманського національного університету садівництва, середньодобова температура третьої декади лютого становила $+3,6^{\circ} \mathrm{C}$, сума опадів - 12,5 мм. Влітку, у другій декаді серпня, 3 середньодобовою температурою $+21,0{ }^{\circ} \mathrm{C}$ та сумою опадів - 14,4 мм, виконували повторне окулірування.

Живці брали завдовжки 10-15 см із одним-двома міжвузлями. Зріз робили гострим лезом садового ножа завдовжки від 1,5 до 5,0 cм, залежно від живця прищепи і його довжини після останнього вузла. Обв'язували поліетиленовою стрічкою завширшки 1,0-2,0 см. Садовим варом не користувались. Після щеплення огляд щеп прово- 
дили регулярно через 5-10 діб упродовж вегетаційного періоду, починаючи 3 другої декади березня. Середньомісячна температура березня становила $+4,1^{\circ} \mathrm{C}$, квітня $+8,7^{\circ} \mathrm{C}$, з сумою опадів за місяць - 54,7 мм та 69,2 мм, відповідно. У міру проростання сплячих бруньок підщепи, їх обламували до повного знищення в тих екземплярів, які добре зрослись. За утворенням на щепі ростових гілочок та за інтенсивністю їх росту встановлювали ступінь зростання прищепи з підщепою і можливість послаблення чи повне зняття обв'язки. Внаслідок інтенсивного росту щеп молоді пагони потребували підв'язування, їхньої пінціровки та зменшення листової площі, для збереження щепи до повного зростання 3 підщепою та формування крони $[2,8]$.

\section{Результати дослідження та їх обговорення}

Під час ранньовесняного щеплення декоративних форм на штамби U. laevis найбільший вихід щеп $(98,5 \%)$ був у разі використання копулювання способом "модифікований (СВФ) поліпшений вприклад" в $U . g$. 'Rubra'. А на штамби U. glabra найкращий відсо- ток (99,0-100 \%) - в U. g. 'Rubra' та U. g. 'Pendula' відповідно (табл. 1).

Під час окулірування в першій декаді серпня вищий вихід щеп $(80,5 \%)$ відзначено в $U . g$. 'Pendula' (рис. 1$)$ та $U . g$. 'Rubra' $(79,0 \%)$ на підщепі U. glabra, однак істотної різниці між ними не відзначено. Найнижчий відсоток $(39,5 \%)$ отримано в U. g. 'Crispa Pyramidalis'. Але, порівняно з ранньовесняним окуліруванням, цей результат є середнім. Так, у разі щеплення U. g. 'Crispa Pyramidalis' в останній декаді лютого - другій декаді березня, найкращими відзначено такі способи копулювання: "поліпшений вприклад" (87,0\%), "модифікований (СВФ) поліпшений вприклад" (89,5 \%) та "вприклад" (75,5 \%). Менші показники виходу щеп відзначено після окулірування (52,5 \%). Прищепним матеріалом слугували живці, термін зберігання яких був мінімальним (до десяти діб) у холодильній камері при температурі близько $0 \mathrm{C}$. В якості підшепних штамбів використовували сіянці $U$. glabra та $U$. laevis. Живці брали довжиною см із однимдвома міжвузлями. Зріз робили гострим лезом садового ножа довжиною від 1,5 до 5,0 см, залежно від живця прищепи і його довжини після останнього вузла.

Табл. 1. Вихід щеп декоративних форм Ulmus за різних періодів щеплення на підщепу U. glabra, \%

\begin{tabular}{|c|c|c|c|c|c|c|}
\hline \multirow{3}{*}{ Прищепа } & \multicolumn{4}{|c|}{ Ранньовесняний період } & \multirow{3}{*}{$\begin{array}{c}\text { Влітку } \\
\text { окулірування }\end{array}$} & \multirow{3}{*}{$\begin{array}{c}\text { Середні показни- } \\
\text { ки виходу щеп за } \\
\text { культиварами }\end{array}$} \\
\hline & \multicolumn{3}{|c|}{ копулювання } & \multirow[b]{2}{*}{ окулірування } & & \\
\hline & $\begin{array}{c}\text { поліпшений } \\
\text { вприклад }\end{array}$ & $\begin{array}{c}\text { модифікований (СВФ) } \\
\text { поліпшений вприклад }\end{array}$ & вприклад & & & \\
\hline U. g. 'Pendula' & 95,5 & 100 & 89,0 & 96,0 & 80,5 & 92,2 \\
\hline U. g. 'Albo-variegata' & 77,5 & 80,0 & 63,0 & - & - & 73,5 \\
\hline U. g. 'Crispa Pyramidalis' & 87,0 & 89,5 & 75,5 & 52,5 & 39,5 & 68,8 \\
\hline U. g. 'Rubra' & 98,5 & 99,0 & 98,0 & 97,0 & 79,0 & 94,3 \\
\hline $\begin{array}{l}\text { Середні показники за спо- } \\
\text { собом щеплення }\end{array}$ & 89,6 & 92,1 & 81,4 & 81,8 & 66,3 & 82,2 \\
\hline $\mathrm{HIP}_{05}$ & 4,5 & 4,6 & 4,1 & 4,1 & 3,3 & 4,1 \\
\hline
\end{tabular}
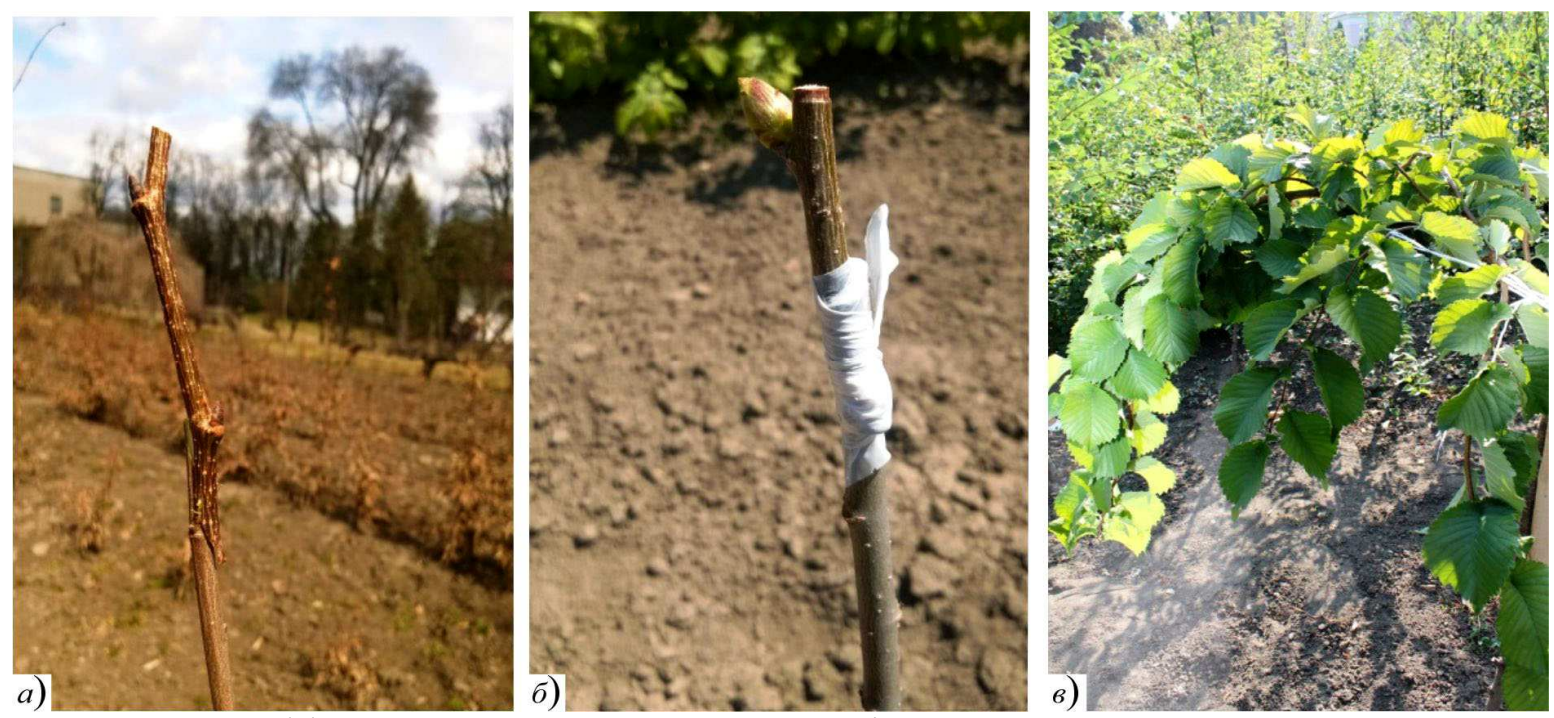

Рис. 1. Щеплення U. g. 'Pendula', виконане копулюванням способом "поліпшений в приклад"

Треба відзначити, що всі декоративні форми видів роду Ulmus, окрім U. g. 'Crispa Pyramidalis', за всіх способів щеплення добре приживались на підщепі трирічних сіянців U. glabra і внаслідок цього забезпечувались досить високі показники виходу щеп - 63,0-100 \%.

На підставі наших досліджень встановлено, що найкращий вихід щеп отримано 3 використанням в ранньовесняний період таких способів щеплення: окулірування та копулювання способом "модифікований (СВФ) поліпшений вприклад". Найбільший вихід щеп зафіксовано в таких декоративних форм: U. g. 'Pendula',
$U$. g. 'Albo-variegata', U. g. 'Rubra', а найнижчий - в U. g. 'Crispa Pyramidalis'.

Під час ранньовесняного щеплення декоративних форм на підщепу U. laevis (табл. 2) найбільший вихід щеп $(98,5 \%)$ відзначено в декоративної форми U.g. 'Rubra' та $U . g$. 'Pendula' $(97,5 \%)$ за копулювання способом "модифікований (СВФ) поліпшений вприклад". Незначну різницю спостерігаємо при копулюванні способом "поліпшений вприклад" у декоративних форм $U$. g. 'Pendula' та $U$. g. 'Rubra', що становить 95,0\% та 94,0 \% відповідно. Найнижчий відсоток приживлюва- 
ності виявлено в $U . g$. 'Crispa Pyramidalis' при копулюванні способом "вприклад", що становить 51,5\%. Найкращим способом для цієї форми є "модифікований (СВФ) поліпшений вприклад", за якого вихід щеплених рослин становить $66,0 \%$. Цей же спосіб є найкращим i для декоративної форми $U . g$. 'Albo-variegata', що становить 79,0 \% (рис. 2), а найнижчу приживлюваність виявлено під час копулювання способом "вприклад".

При щепленні в першій декаді серпня найбільший вихід щеп $(77,5 \%)$ відзначено в $U . g$. 'Rubra'. Незначне зменшення спостерігалось в декоративної форми $U . g$.
'Pendula' - 76,0 \%. Найнижчий вихід (38,5 \%) спостережено в U. g. 'Crispa Pyramidalis'.

При щепленні традиційними методами декоративних форм видів роду Ulmus на U. laevis кращі результати виходу щеп (76,0-98,5 \%) відзначено в таких декоративних форм - U. g. 'Pendula' та U. g. 'Rubra'. Середні показники $(60,0-79,0 \%)$ зафіксовано в $U . g$. 'Albo-variegata'. Варто зазначити, що $U . g$. 'Crispa Pyramidalis', оскільки і при щепленні на $U$. glabra, показала найнижчий вихід щеп, який коливається в межах 38,5-66,0 \% (табл. 2).

Табл. 2. Вихід щеп декоративних форм Ulmus за різних періодів щеплення на підщепу U. laevis, \%

\begin{tabular}{|c|c|c|c|c|c|c|}
\hline \multirow{3}{*}{ Прищепа } & \multicolumn{4}{|c|}{ Ранньовесняний період } & \multirow{3}{*}{\begin{tabular}{|c|} 
Влітку \\
окуліру- \\
вання \\
\end{tabular}} & \multirow{3}{*}{$\begin{array}{l}\text { Середні по- } \\
\text { казники ви- } \\
\text { ходу щеп за } \\
\text { культиварами }\end{array}$} \\
\hline & \multicolumn{3}{|c|}{ Копулювання } & \multirow{2}{*}{$\begin{array}{l}\text { окуліру- } \\
\text { вання }\end{array}$} & & \\
\hline & $\begin{array}{c}\text { поліпшений } \\
\text { вприклад }\end{array}$ & $\begin{array}{c}\text { модифікований (СВФ) } \\
\text { поліпшений вприклад }\end{array}$ & вприклад & & & \\
\hline U. g. 'Pendula' & 90,5 & 97,5 & 87,5 & 91,5 & 76,0 & 88,6 \\
\hline U. g. 'Albo-variegata' & 75,5 & 79,0 & 60,0 & - & - & 71,5 \\
\hline U. g. 'Crispa Pyramidalis' & 61,0 & 66,0 & 51,5 & 46,5 & 38,5 & 52,7 \\
\hline U. g. 'Rubra' & 94,0 & 98,5 & 96,5 & 89,5 & 77,5 & 91,2 \\
\hline Середні показники за способом щеплення & 80,3 & 85,3 & 73,9 & 75,8 & 64,0 & 76 \\
\hline $\mathrm{HIP}_{05}$ & 4,0 & 4,3 & 3,7 & 3,8 & 3,2 & 3,8 \\
\hline
\end{tabular}

Отже, для швидкого розмноження декоративних форм видів роду Ulmus найкращими в ранньовесняний період вегетації є окулірування і такі методи копулювання: "поліпшений вприклад", "модифікований (СВФ) поліпшений вприклад" і "вприклад".

Аналізуючи дані табл. 1 та 2, встановлено, що для усіх досліджених декоративних форм можна використовувати в ролі підщепи як U. glabra, так і U. laevis. За використання плакучої форми $U . g$. 'Pendula' у вигляді солітера в різних ландшафтних композиціях, для щеплення потрібно використовувати рівні штамби самосіву U. glabra і U. laevis різних висот.

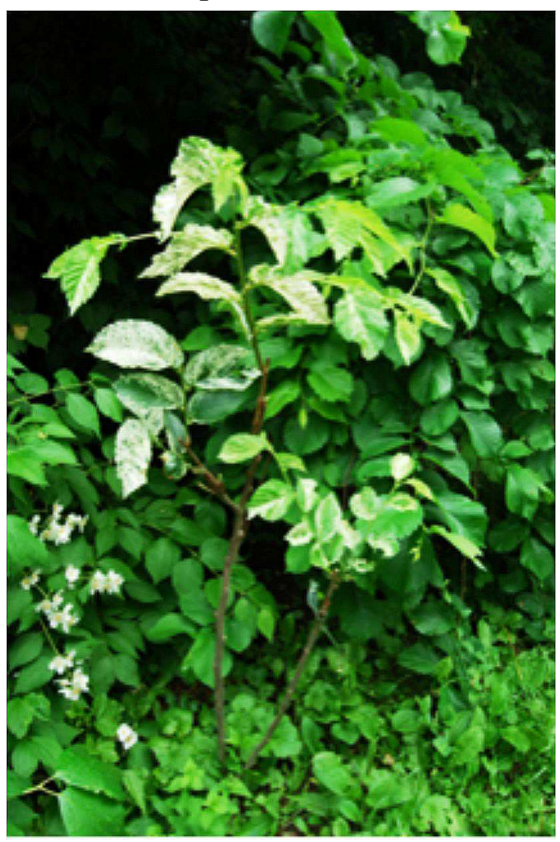

Рис. 2. Щеплення способом копулювання "модифікований (СВФ) поліпшений вприклад" декоративної форми $U$. g. 'Albo-variegata'

\section{Висновки}

1. Для швидкого розмноження декоративних форм в'язів можна рекомендувати у ранньовесняний період вегетації застосування окулірування та таких методів копулювання: "вприклад", "поліпшений вприклад" і "модифікований В. Ф. Собченком поліпшений вприклад".

2. Для усіх досліджених декоративних форм видів роду Ulmus можна використовувати у ролі підщепи як U. glabra, так і U. laevis.

3. Для розмноження декоративних форм $U . g$. 'Pendula', $U$. g. 'Albo-variegata', $U . g$. 'Crispa Pyramidalis' та $U . g$. 'Rubra' у ранньовесняний період рекомендуємо використовувати як підщепи U. glabra та спосіб копулювання "модифікований (СВФ) поліпшений вприклад", який дає змогу отримувати понад 80,0 \% прищепленого матеріалу.

\section{References}

1. Baiura, O. M. (2010). Vegetative reproduction of ornamental forms of common ash (Fraxinus excelsior L.) by the method of engrafting. Scientific Bulletin of UNFU, 20(13), 23-28.

2. Ermakov, B. S. (1981). Razmnozhenie drevesnykh i kustarnikovykh rastenii zelenym cherenkovaniem. Kishinev: Shtiintca, $226 \mathrm{p}$.

3. Evtushenko, Yu. V. (2016). Some peculiarities of Aesculus Carnea Hayne reproduction. Scientific Bulletin of UNFU, 26(7), 3845. https://doi.org/10.15421/40260705

4. Kozlov, V. H. (2003). Introduktsiia vydiv i form buka (Fagus L.) u Pravoberezhnomu Lisostepu Ukrainy ta perspektyvy vykorystannia yikh $v$ kulturi. Uman: Vyd-vo "Urvyshche", 132 p. [In Ukrainian].

5. Maslovata, S. A., Kulbitskyi, V. L., \& Osipov, M. Y. (2019). Systematic and phylogenetic relations of Ulmus L. Scientific $\begin{array}{lll}\text { Bulletin } & \text { of } & \text { 29(5), }\end{array}$ https://doi.org/10.15421/40290510

6. Maslovata, S., \& Shlapak, V. (2016). The features of seasonal shoot growth of types and forms of the Genus Ulmus L. in the conditions of Right Bank forest-steppe of Ukraine. Scientific Bulletin of UNFU, 26(7), 120-126. https://doi.org/10.15421/40260719

7. Molisch, H. (1922). Pflanzenphysiologie als Theorie der Gartnerei, 5. Auff. Jena. $128 \mathrm{p}$.

8. Shpak, N. P. (2019). The use of Different Methods of Reproduction of Sorbus torminalis (L.) Crantz for Renewal in Fresh oak Forests of South Podillya Forest-Steppe of Ukraine. Scientific Bulletin of UNFU, 29(7), 17-20. https://doi.org/10.15421/40290703

9. Sobchenko, V. F. (2004). Rozmnozhennia dekoratyvnykh ta plodovykh roslyn metodom shcheplennia svizhozrizanymy zhyvtsiamy v period spokoiu. Visnyk Lvivskoho universitetu, 36, 175185., 175-185. [In Ukrainian]. 


\section{VEGETATIVE PROPAGATION OF ORNAMENTAL FORMS OF SPECIES OF THE GENUS ULMUS L.}

An important task for expanding the range of woody plants, which will contribute to the preservation of their biodiversity and rational use of plant resources, is to establish their reproductive capacity and the most optimal methods of propagation. The article deals with the results of research and generalization of work on the peculiarities of vegetative propagation and cultivation of planting material of species and forms of the genus Ulmus in the Right Bank Forest-Steppe of Ukraine. Vegetative propagation of ornamental forms of Ulmus L. species using the inoculation and grafting methods such as chip grafting, improved chip grafting and improved chip grafting modified by V. F. Sobchenko in the early spring period and summer budding in the first decade of August on the rootstocks U. laevis and U. glabra was studied. During budding in the first decade of August, U. g. Pendula (80.5\%) and U. g. Rubra $(79.0 \%)$ on the U. glabra rootstock had the best survivability, while no significant difference was observed between them. The lowest survivability $(39.5 \%)$ was the characteristic of the decorative form of $U$. $g$. Crispa Pyramidalis. It should be noted that almost all decorative forms of species of the genus Ulmus, except $U$. g. Crispa Pyramidalis, with all methods of inoculation had a fairly high survival rate when grafting three-year-old seedlings of $U$. glabra $(63.0-100 \%)$. According to the results of grafting decorative forms of species of the genus Ulmus on $U$. laevis, the best results were obtained in such decorative forms as $U . g$. Pendula and $U$. g. Rubra (76.0-98.5\%). The average indices of survivability were observed in $U . g$. Albo-variegata (60.0-79.0\%). We should also mention that $U$. g. CrispaPyramidalis, as well as during U. glabra grafting, had the lowest survivability (38.5-66.0\%). Under the propagation of decorative forms of $U . g$. Pendula, $U . g$. Albo-variegata, $U . g$. Crispa Pyramidalis and $U . g$. Rubra with grafting shows the highest yield of cuttings on the rootstock $U$. glabra is $63-100 \%$, when using the budding method in late February - early March. Therefore, for the propagation of all studied decorative forms of species of the genus Ulmus the best in the early spring growing season were the inoculation and such methods of inoculation and grafting as improved chip grafting, improved chip grafting modified by V. F. Sobchenko and chip grafting. It is advisable to use U. glabra and U. laevis as rootstocks.

Keywords: propagation; grafting; budding; inoculation. 